Session 1725

\title{
Capstone Design through Cooperative Learning
}

\author{
Sigurd L. Lillevik \\ Electrical Engineering and Computer Science Department \\ University of Portland \\ Portland, OR 97223
}

\begin{abstract}
Cooperative learning activities for a yearlong capstone design sequence include many of the same practices used by design teams in industry. For this course, teams of $3-4$ students solve an open-ended problem under the guidance of a faculty advisor and in conjunction with practicing professionals. Specific cooperative learning activities include in-class exercises, weekly status, approval meetings, team meetings, technical documents, program reviews, web sites, change control, prototyping, and final presentations. Assessment data from the students, faculty advisors, and industry representatives indicate that the course structure improves writing, presentation, interpersonal, professional, and higher-level thinking skills.
\end{abstract}

\section{Introduction}

Student-centered learning paradigms and, specifically, cooperative learning activities have proven to be very effective teaching methods. This paper reports on applying cooperative learning techniques to a yearlong capstone design sequence. Using these methods, instructors who teach or whom are planning to teach a capstone design sequence, will acquire an understanding of what works well at one university and may wish to adapt the practices to their environment.

The specific setting for this course is a small, private school located in the Northwest and in a city with numerous high-technology companies. As a result, the methods may or may not be applicable to a large, state school and, depending upon location, interaction with practicing professionals may be problematic. We will provide an overview of the design course but will not go into intricate details such as individual lecture topics, document contents, project funding, laboratory space, and equipment.

The first section discusses instructional objectives and sets the motivation for the next section, course structure. Here, we define some of the background information such as credit hours, team size, etc. In the subsequent section, we review the common design process and map it to the 
yearlong schedule. This is followed by a discussion on cooperative learning where specific activities are defined and illustrated. Finally, we complete the paper with a short explanation of student grading and course assessment.

\section{Instructional Objectives}

During the past quarter century, faculty in the Electrical Engineering and Computer Science Department at the University of Portland have developed and refined a yearlong, capstone design project sequence. All senior students must complete this two-semester course as a requirement for graduation. A class like this is very common at many universities ${ }^{1}$ and you will see that several of the objectives are familiar.

In Table 1, we list the specific instructional objectives for the course and categorize them according to Bloom's taxonomy ${ }^{2}$ of educational objectives. We see that most of the objectives (all but 4 and 5) include the higher-level skills analysis, synthesis, and evaluation. Conversely, Objectives 4 and 5 focus on oral and written communication skills.

Table 1. Instructional objectives and Bloom's classification.

\begin{tabular}{|c|c|c|c|c|c|c|}
\hline Instructional Objectives & $\begin{array}{l}\frac{0}{00} \\
\frac{0}{0} \\
\frac{0}{3} \\
0 \\
\Xi\end{array}$ & 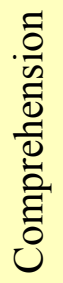 & $\frac{\overline{0}}{. \frac{0}{\tilde{\Xi}}}$ & 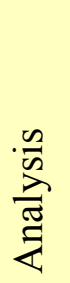 & 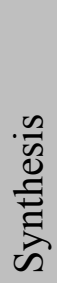 & 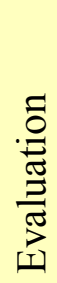 \\
\hline 1. Apply a development process to a design project & & & $\mathrm{X}$ & & & \\
\hline 2. Design a solution to an open-ended problem & & & & $X$ & $\mathrm{X}$ & $\mathrm{X}$ \\
\hline 3. Implement, debug, and evaluate a prototype & & & & $\mathrm{X}$ & $\mathrm{X}$ & $\mathrm{X}$ \\
\hline 4. Deliver effective technical presentations & $\mathrm{X}$ & $\mathrm{X}$ & & & & \\
\hline 5. Write and publish technical documents & $X$ & $\mathrm{X}$ & & & & \\
\hline 6. Create, publish and maintain a project web site & & & & & $\mathrm{X}$ & \\
\hline 7. Apply modern productivity tools & & & $\mathrm{X}$ & & & \\
\hline 8. Optimize an individual's role to meet group objectives & & & & & & $\mathrm{X}$ \\
\hline
\end{tabular}

In a sense, the course provides a bridge for the students to cross between the academic world on one side and the technical professional world on the other. It requires the student to integrate much of their previous coursework and use it to solve an open-ended design problem in a team setting. 
Objective 1 requires the students to follow a specific development process throughout the year. In fact, it is a process that models as closely as possible the steps that many product teams use in many high-technology companies. Unfortunately, logistics prohibit some of the marketing and manufacturing steps.

Solving an open-ended problem, Objective 2, requires the student to use their mathematic, science, and engineering fundamentals to propose, analyze, and evaluate alternate solutions. Often, the student teams will model several possible design options, generate performance data, and select the solution based on meeting required specifications.

This capstone design sequence involves more then a theoretical design. In Objective 3, the students build, debug, and evaluate a prototype of their design. This entails significant laboratory experimentation and crossing into the realm of "reality." It is amazing how the simplest design becomes more difficult and multi-disciplinary when you must "get it to work."

As discussed above, Objectives 4 and 5 focus on communications skills. During the year, the student teams prepare several technical documents to assist with the design process. Faculty advisors review each document prior to an approval meeting attended by practicing professionals. Also, each student must present to their peers and faculty several program reviews. Both of these objectives involve significant "learn by doing" experience.

Each student team maintains a project web site, Objective 6, that contains an up-to-date repository for all project information. It includes pages for documents, meeting minutes, presentations, schedule, and other data such as critical design files. In the not to distant past, this information was compiled into a set of project notebooks. Now, it is online and instantly available.

Practicing professionals must know how to use the tools of the trade. Specifically, the students use the following: word processor, spreadsheet, presentation, web authoring, and scheduling applications. In addition, teams use a variety of other contemporary modeling and simulation software applications.

The last objective, Objective 8, involves the ability to work as a team with trust and respect for each other. In particular, a student must learn how to assume responsibility, set challenging goals, listen to all ideas and viewpoints, and confront and resolve conflicts. Each semester, one team member is designate the Team Lead. This allows for the opportunity to develop leadership characteristics such as delegation, attention to detail, setting standards, and general project coordination.

\section{Course Structure}

A number of possible course structures exist ranging from informal-theoretical to formal-applied. This capstone design sequence takes on the latter and a more formal, process structure with emphasis on application, or prototyping. As shown in Table 2, the sequence contains several attributes to fully describe the structure and format. 
Table 2. Capstone design course structure.

\begin{tabular}{|ll|}
\hline Attribute & Structure \\
\hline Motivation & Simulate industry environment \\
Key Influences & Andy Grove and the Intel Corporation \\
Length and Credits & Two semesters, 3 credits each semester \\
Majors & Computer Science and Electrical Engineering \\
Instruction & Instructor, faculty advisors, industry representatives \\
Teams & Student-formed, 2-4 students-per-team, 10 - 12 teams-per-year \\
Projects & $\begin{array}{l}\text { Student selected, multidisciplinary, ranges widely between software } \\
\text { and hardware }\end{array}$ \\
Design Process & Common, milestones, schedule, approvals, change control \\
\hline
\end{tabular}

Because of the author's affiliation with the Intel Corporation for several years, he was motivated to provide an academic environment as close as possible to professional practice. Many of the cooperative learning activities described in the next section result from this affiliation. And no single individual has had a greater impact on the Intel Corporation then Andy Grove. ${ }^{3-4}$

Moreover, his influence is pervasive across the high-technology industry and across this course.

The course spans two semesters or an entire year. Both Computer Science and Electrical Engineering senior students must complete the course as a requirement for graduation.

Essentially, the course is team taught by the Electrical Engineering and Computer Science faculty. One faculty member serves as the course instructor but each student team works under the tutelage of a faculty advisor. In addition, each team interacts with a practicing professional in the local area. These industrial representatives volunteer their time and talents for the duration of the year and are active participants in the design process. They offer technical consulting, documentation review, feedback, approval ratification, and general mentoring. The course instructor handles the classroom lectures, manages the overall class, and assigns grades.

There exist several approaches to forming senior design teams. ${ }^{5}$ Contrary to recommendations, the students select their team members. This approach has been used for several years and has become expected. As a result, student teams tend to cluster by grade point average and by ethnicity. Team size averages 3 students but on an exception basis may include only 2 and up to 4. Teams of 2 miss out on some of the team dynamics and teams of 4 incur additional logistic challenges (e.g., try to schedule a team meeting). A typical senior class consists of say $30-40$ students, so that translates into around $10-12$ teams. With ten full-time faculty, each faculty 
member advises about 1 or 2 teams-per-year. Also, the course requires around $10-12$ industry representatives.

The projects range widely from pure software applications, to VLSI chip fabrication, microcontroller applications, analog control systems, digital logic, and combinations of multiple technologies. It is not unusual for a team to contain both Computer Science and Electrical Engineering majors and involve a VLSI chip, microcontroller, and significant software. The faculty review the project proposals at the beginning of Fall Semester to evaluate the "degree of difficulty." In some cases, we ask the team to back off on their expectations. We have never turned down a proposal because the difficulty was too simple. This is an important and critical step because you do not want to set a team up for failure.

The final attribute in Table 2, Design Process, is common to all teams. This becomes a challenge to orchestrate because of differing technologies but must be adhered to for logistic reasons. Basically, all teams progress along the design timeline in parallel irregardless of the technologies involved in the project.

\section{Design Process and Schedule Overview}

The design process for product development is illustrated in Figure 1 and includes five distinct phases: define, design, prototype, evaluate, and production. The diagram is in the shape of a funnel to indicate that as time moves on the design team becomes more focused. Also, note that the transition from one phase to the next is really iterative and occurs over some (short) period of time.

Due to time constraints, course load, and other issues, only the Design and Prototype phases receive primary focus. Ideally, students would experience the up-front marketing and back-end manufacturing phases but there simply is not enough time to do it all. Further, it is not practical to actually manufacture and sell a product. Selected marketing and manufacturing topics are presented in the lecture portion of the course.

Students begin the year in the Define phase and prepare a Functional Specification that describes what the project does. Next, they enter the Design phase and publish a Project Plan that contains a roadmap (schedule, assumptions, contingencies, etc.) and methods for how they will complete the project. The final Fall Semester activity entails the Design Release. Here, the team reviews the completed design with their advisor and industry representative as a checkpoint that it will meet specifications and does not contain any escapes or flaws. The design review signals the purchase of parts, chip fabrication, and low-level design activities.

Spring Semester involves the Prototype and Evaluation phases. First, students prepare a Theory of Operations document that describes, technically, how the design works. Many bugs are caught during the writing of this documents and it serves as a guide for further prototype debug. Once the prototype is fully debugged, the students conduct limited evaluation. Sometimes, teams never get all of the bugs out and the prototype only marginally functions. But most teams successfully meet their requirements and some even exceed them. 


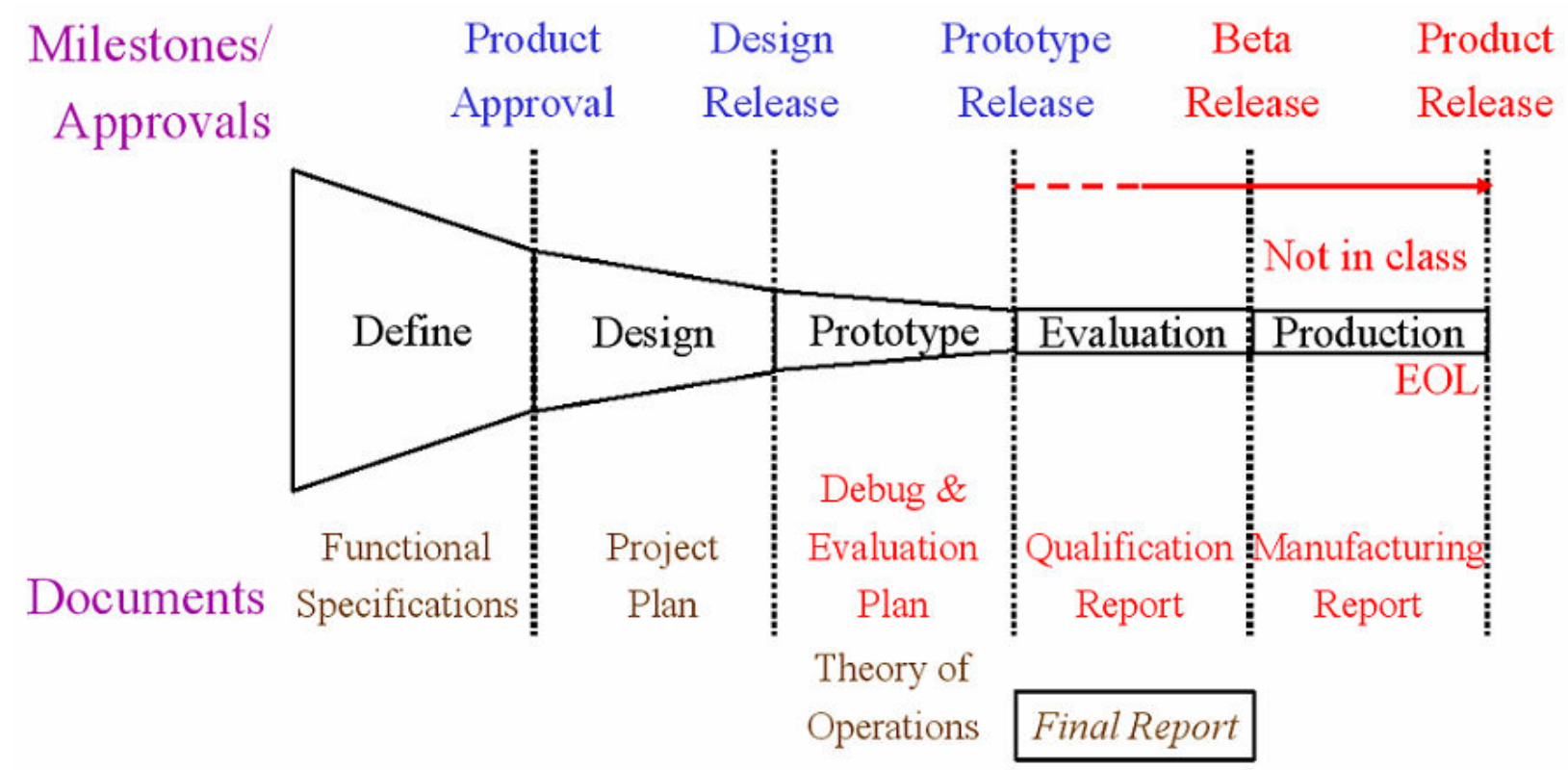

Figure 1. Design process overview.

Near the end of Spring Semester and about a month prior to graduation, the students present the results of their design projects in a conference-like setting during the university-wide Founder's Day celebration. This event honors the school's roots and recognizes the accomplishments of the senior graduates. All classes are cancelled and the public, family-friends, and industry representatives are invited. Lastly, the students prepare a summative, Final Report, that is published as a School of Engineering Technical Report. Before the seniors graduate, they meet with the Junior class over pizza and present a post mortem of their project activities. They offer the next class words of wisdom and suggestions for what worked well and what to avoid.

\section{Cooperative Learning Activities}

The advantages of active learning applied to design courses are well documented. ${ }^{6}$ Similarly, cooperative learning ${ }^{7,8}$ or students working together over a significant period of time with individual responsibilities results in improved:

- student-faculty interactions

- student-student interaction

- information retention and grades

- high-level thinking skills

- attitude toward subject and motivation to learn it

- teamwork and interpersonal skills

- communication skills

- understanding of professional environment 
- self esteem and lower level of anxiety

- race and gender relations

- class attendance

But if you look closely at cooperative learning, it curiously parallels the methods of a product design team in industry. So, for a capstone design course sequence, it follows that cooperative learning activities directly apply.

For this course, the cooperative learning activities are summarized in Table 3. Notice that some of these look familiar (in-class exercises) and each of these activities include a team goal, individual roles, uses interpersonal skills, and accountability.

Table 3. Design course cooperative learning activities

\begin{tabular}{|ll|}
\hline Activity & Description \\
\hline In-class Exercises & Brain-storming and problem solving \\
\hline Weekly Status & Accomplishments, plans, issues \\
\hline Approval Meetings & Product approval, design release, prototype release \\
\hline Team Meetings & With and without faculty advisor, formal and informal \\
\hline Technical Documents & $\begin{array}{l}\text { Functional Specifications, Project Plan, Theory of Operations, Final } \\
\text { Report }\end{array}$ \\
\hline Program Reviews & Monthly, accomplishments-plans-issues \\
\hline Web Site & Central repository for all project data \\
\hline Change Control & Requests, board review, approval \\
\hline Prototyping & Implement, debug, evaluate \\
\hline Final Presentations & Founder's Day, post mortem with Junior Class \\
\hline
\end{tabular}

During the lecture portion of the class, students work in groups of three to either brain-storm or solve a problem. For example, when introducing the motivation for preparing a Functional Specification, each group is asked to come up with reasons why a design team may want to document their requirements. Each team then shares their answers with the entire class and the instructor summarizes.

To stress the importance of communication, each student prepares a weekly status report. It include the student's, not the team's, weekly accomplishments, plans for the next week, and a list of any issues. This short email takes around 5 minutes to prepare and is sent to the instructor, advisor, and other team members. Weeklies are very helpful to see who is doing what and often brings problems to the surface. 
The purpose of approval meetings is to assure that the student team is following the design process and not slipping their schedule. The team lead calls the meeting, prepares the agenda, chairs the meeting, captures action items, and sees that minutes are prepared and posted on their project web site. Each of the milestones require an approval meeting and often this involves a technical document. The advisor is responsible for decision making in conjunction with the industry representative. Most approval meetings involve a teleconference but many are face-toface with the industry representative and, sometimes, at their facility or plant.

Each team meets weekly with their faculty advisor. These meetings, typically $30-60$ minutes, are informal and provide an opportunity for the students to ask a technical question or describe a problem in detail. For the advisor, they can ask the student team about progress, review draft documents, or investigate a potential issue.

During the yearlong course, the students prepare four technical documents: two each semester. They must follow a specific format and generally entail $10-15$ pages. Students first submit to their advisor a Revision 0.9. After review and feedback, the revision changes to 0.95 and it is sent to the industry representative. During the approval meeting, the document is further critiqued and suggestions for changes discussed. When the final modifications are completed, the document moves to Revision 1.0 and, thereafter, requires a change request for significant alterations. As the year progresses, a change to one document may result in a ripple of changes to earlier documents.

Each month, the teams prepare a Program Review describing their accomplishments, plans for next month, any issues, and questions-answers. On a rotating basis, one student presents the review to the class (faculty in attendance). Usually, the Program Review contains the integration of each team member's weeklies over the past month. Some of the question and answer sections become quite lively. The monthly granularity provides the team an opportunity to both reflect on the past and plan for the future. The student presenter receives a critique from the instructor using an evaluation form from the Speech Department.

Each team creates, publishes, and maintains a project web site. The instructor provides a "starter" web that uses a standard theme and page hierarchy. Teams are encouraged not to customize the web, a time sink, or use it for other purposes. It contains a home parent-page and child-pages for documents, meeting minutes, presentations, schedule, and other information. Each team can only publish their web while the instructor has full access rights to all student web folders.

Once a document or design has been approved, a significant modification requires a change request and approval. A request is not required for minor changes. The request describes why the change is required and what the impact will be to the project. A change control board reviews and approves changes. The board consists of two students on a rotating basis and the instructor. Poor time management is not a valid reason for a change. Most changes result from poor assumptions and require modification to the feature set defined in the Functional Specification. Turn-around time averages about a day. Change control avoids "feature creep", adds credence to the approval process, and holds the team accountable for their actions and results. 
Finally, significant out-of-class time is devoted to prototyping. This is where the "rubber meets the road" and is sometimes a source of individual and team frustration. Conversely, it is also a point in the student's development of great joy and pride of accomplishment. Spring Semester often involves significant debugging time in the laboratory and, sometimes, other classes suffer. Within the department, faculty take this into account but it is a challenge.

\section{Student Evaluation}

One of the difficulties in cooperative learning teams, is to fairly, accurately, and equitably evaluate individual performance and assign student grades. How do you separate out an individual's accomplishments from the team? Many approaches start with a team grade and then the individual grades are factored up or down. Often, peer review is an essential component of the evaluation..$^{9}$ As shown in Table 4, peer review is but one of four factors that influence a student's grade. The others include the advisor, industry representative, and the instructor. Ultimately, the instructor is responsible for assigning grades.

Table 4. Student evaluation components.

\begin{tabular}{|ll|}
\hline Component & Description \\
\hline Peer & $\begin{array}{l}\text { Students evaluate each other on effort, contribution, strengths, areas } \\
\text { for improvement }\end{array}$ \\
\hline Advisor & Assigns a numeric score and recommends a grade for each student \\
\hline Industry Representative & Provides feedback on the team's performance \\
\hline Instructor & $\begin{array}{l}\text { Integrates all data, assures consistency, prepares individual reviews, } \\
\text { assigns student grades }\end{array}$ \\
\hline
\end{tabular}

Students evaluate, confidentially, both themselves and the other members in the team. They provide an overall rating and offer specific comments, with examples, on contribution, strengths, and areas for improvement. Both the instructor and advisor receive these peer evaluations. The scores for each team are averaged and each individual averaged. An individual weight is then found as a ratio of the individual-to-team score.

The next component of student evaluation is prepared by the advisor. After all, they meet with the team each week and "should" understand the individual contributions. Using the rubric found in Table 5, the advisor evaluates each individual student, gives them a score, and suggests a grade. Notice that $60 \%$ of the score is based on the student meeting their schedule and $40 \%$ on their technical contribution. These metrics and values are similar to many performance appraisal rubrics found in professional practice. On the job, meeting one's schedule is extremely important. 
Table 5. Student evaluation rubric.

\begin{tabular}{|lcl|}
\hline Criteria & $\begin{array}{l}\text { Max } \\
\text { Points }\end{array}$ & Definition \\
\hline 1. Schedule (60\%) & 20 & $\begin{array}{l}\text { Evaluates the process component } \\
\text { Did the team meet their schedule? } \\
\text { Were there good reasons why they did not? }\end{array}$ \\
\hline 1.1 Milestones & 20 & $\begin{array}{l}\text { Were the documents well written in terms of content, } \\
\text { organization, style, and editing? }\end{array}$ \\
\hline 1.2 Documents & 10 & $\begin{array}{l}\text { Did the program reviews keep you up to date on } \\
\text { accomplishments, plans, and issues? }\end{array}$ \\
\hline 1.3 Program Reviews & 10 & $\begin{array}{l}\text { Did the web site contain all project information? Was it } \\
\text { updated regularly? Were weeklies submitted regularly and } \\
\text { on time? Were meeting minutes accurate and timely? }\end{array}$ \\
\hline 1.4 Web site \& misc. & & Evaluates the technical component \\
\hline 2. Technical (40\%) & 20 & What is the degree of difficulty in their project and design? \\
\hline 2.1 Depth & 20 & Does the project and design address all technical concerns? \\
\hline 2.2 Breadth & 100 & \\
\hline TOTAL & & \\
\hline
\end{tabular}

The third component is provided by the industry representative. They are asked to comment on the quality of the design and the overall effectiveness of the team. Usually, they can not comment on individuals. The information provided by the industry representatives is largely anecdotal but does serve as an additional data point.

The instructor collects information from the three sources, checks for consistency between the three evaluations, and for equity between all of the teams and students. Unless there is some disagreement, the advisor's suggested grade usually becomes the student's assigned grade. In cases of disagreement (about $5 \%$ ), the instructor and advisor confer to resolve the final grade. Usually, one or the other has some additional information that has not been shared and it takes only a little time to come to agreement. Lastly, the instructor creates a written review for each student (about one page in length) that contains their grade, numeric score, and a short narrative discussing the student's contribution, strengths, and areas for improvement. Edited excerpts from the peer, advisor, and industry representative evaluations are provided to illustrate the points in the review. These reviews are modeled after performance appraisals in professional practice.

\section{Course Assessment}

Course objectives are assessed using evaluations from the students, faculty, and industry representatives. The student evaluations are standardized across the School of Engineering and administered by the Dean's office. They contain a number of multiple choice responses and a section for short answers. Conversely, the faculty and industry representative evaluations are administered by the instructor. Questions focus on course strengths and recommendations for improvement plus expected individual involvement and role. 
Table 6 contains a summary of assessment data from academic year 2002 - 2003. Its contains an abstract of information from the student, faculty, and industry representative evaluations. In general, the cooperative learning approach appears to work well but the expectations of the students seems to keep increasing.

Table 6. Summary of 2002 - 2003 assessment data.

\begin{tabular}{|ll|}
\hline Source & Comments \\
\hline \multirow{3}{*}{ Student Evaluations } & $\begin{array}{l}\text { Gained valuable experience } \\
\text { Class "puts it all together" } \\
\text { Not enough time } \\
\text { Too much "paperwork" }\end{array}$ \\
\hline \multirow{2}{*}{ Faculty Evaluation } & $\begin{array}{l}\text { An intense, realistic preparation for engineering practice } \\
\text { Common design process improves faculty coordination } \\
\text { Class requires significant time commitment } \\
\text { Industry representatives very helpful }\end{array}$ \\
\hline \multirow{2}{*}{$\begin{array}{l}\text { Industry Representative } \\
\text { Evaluation }\end{array}$} & $\begin{array}{l}\text { Student's first large-scope project in team environment } \\
\text { Founder's Day presentations comparable to a technical conference } \\
\text { Not sure how "hard" to push student team } \\
\text { Design process very similar to real-life }\end{array}$ \\
\hline
\end{tabular}

Student comments range widely but, overall, they feel that the capstone design sequence is a valuable learning experience. For many, it is the first time they have taken on a significant project and, as a result, it is the first time they have integrated the skills learned in their earlier courses and "put it all together." Unfortunately, students report that senior design is a difficult class because it is very time consuming. A common complaint is that there is "too much paperwork." Interestingly, many students use their documents (paperwork) as examples when applying for employment or graduate school. Over the years, it appears that the students seem to take on increasingly complex projects and this adds to the time commitment.

The faculty echo many of the student comments and indicate that a common design process allows them to coordinate team activities because they are all in lock-step. From a time commitment, faculty advisors must allocate significant time to the class. It is much more then just a weekly meeting with each of their teams. But overall, faculty report the course improves the student's writing, presentation, interpersonal, professional, and higher-level thinking skills. Lastly, the collaboration with the industrial representative has proven fruitful. They reinforce the goals of the course and instantly add a professional component to the student's activities.

Response from the industrial representatives has been very positive. One summed up his observations by saying "I wish I had taken a class like this when I was in school." A couple of others stated the following. 
The senior project is an essential experience for students before they move into industry, because it is the first large-scope project that many of them have taken on in a team context. It allows them to learn by doing, and to make mistakes in an environment more tolerant than the marketplace.

Besides the technical aspects, just setting up the meetings, enabling communication over the phone/cross-site, and other logistical challenges are good experience and will be relevant once they enter industry. I enjoyed the Founder's Day presentations and felt that was a great way to end the year.

I think this is a great class! It certainly gives the student practical experience and understanding of project life-cycle. The steps (though not the words) are very, very close to how we (name deleted) produce software.

One industry representative asked that the "professors need to come up with a guideline on what is acceptable for the industry representatives to push on or demand." Another commented on lack of adequate warning. "I know it is difficult for the students to plan too far in advance. Most of my meetings came to my attention 1-2 days prior to the meeting date." Both of these concerns have since been addressed and were good suggestions.

On the topic of assessment, the author must add that there remains one problem that plagues all team-taught courses. Unfortunately, the faculty advisor interaction with each team is not consistent. Some feel very strong about the class and its contribution to the student's educational experience. Others look at it as a time sink with little to no reward or recognition. Either way, some faculty are far better advisors then others. We try to compensate for this by not assigning a team we feel is weak to an advisor that is also weak. The rationale is that a strong team will succeed in spite of their advisor. Unfortunately, this rewards the weak advisor with a strong team, may not be fair to the strong team, and helps propagate or reinforce the weak advisor's lack of effort.

We continue to struggle with this dilemma and have under consideration the following proposal. For each semester, instead of one, three-credit course, split the design sequence into a two-credit lecture and a concurrent, one-credit laboratory section. With this approach, the lecture is taught by the course instructor and each faculty advisor teaches a corequisite laboratory section. All students register for the lecture plus a laboratory section taught by their faculty advisor. By formally teaching a laboratory section, all faculty advisors receive recognition for their time and are motivated to take responsibility for the success of their student team. This proposal is presently in the discussion state and not implemented.

\section{Conclusions}

Cooperative learning activities are well suited to a capstone design sequence because they can include many of the same practices adhered to by a design team in industry. For this yearlong course sequence, small teams of 3-4 students solve an open-ended under the guidance of a faculty advisor and in conjunction with practicing professionals from the local high technology 
community. One faculty member serves as the course instructor and coordinates all activities including assigning grades.

Specific cooperative learning activities for the course include: in-class exercises, weekly status, approval meetings, team meetings, technical documents, program reviews, web site, change control, prototyping, and final presentations. Each activity includes a team goal, individual roles, uses interpersonal skills, and team-student accountability.

Assessment data indicate the students feel the course is valuable but one that requires a significant time commitment. Also, students do not like to follow a process or write technical documents. But these are skills that must be mastered for a successful career in professional practice. Likewise, faculty advisors report that the course demands a fair amount of their time with possibly little to no reward or recognition. They report improvement in student writing, presentation, interpersonal, professional, and higher-level thinking skills. Finally, the industry representatives "wish they had a course like this when they attended school." They have all been very supportive and help to reinforce the instructional objectives.

\section{Bibliography}

1. Todd, R.H., et al., "A Survey of Capstone Engineering Courses in North America," Journal of Engineering Education, vol. 84, no. 2, 1995, pp. 165-174.

2. Bloom, B. S., Krathwohl, D. R. (1984). Taxonomy of educational objectives. Handbook I. Cognitive domain. New York: Addison-Wesley.

3. Grove, A. S., Only the Paranoid Survive (1999). New York: Time Warner Books.

4. Grove, A. S., High Output Management (1995). New York: Random House.

5. Shaeiwitz, J. A., "Observations on Forming Teams and Assessing Teamwork," 2003 ASEE Annual Conference and Exposition, Session 3613.

6. Dutson, A., Green, M., Wood, K., and Jensen, D., "Active Learning Approaches in Engineering Design Courses," 2003 ASEE Annual Conference and Exposition, Session 2125.

7. Slavin, R. E. (1995). Cooperative learning: Theory, research, and practice. Boston, MA: Allyn and Bacon.

8. Ted Panitz's home page, a collection of cooperative learning resources, http://home.capecod.net/ tpanitz/.

9. Gehringer, E. F., "Electronic Peer Review Builds Resources for Teaching Computer Architecture,” 2003 ASEE Annual Conference and Exposition, Session 1532.

\section{Biography}

SIGURD L. LILLEVIK, lillevik@up.edu

Dr. Lillevik is an Associate Professor of Computer Science in the School of Engineering at the University of Portland. He joined the university faculty in 2001. Previously, he was an Engineering Manager with the Intel Corporation for seventeen years and designed parallel supercomputers, high-end servers, and processor packaging. 